\title{
Measuring the Effectiveness of E-mail Direct Marketing in Building Customer Relationship
}

\author{
Abdel Baset I. Hasouneh (Corresponding author) \\ Associate Professor of Marketing, Faculty of Administrative and Financial Sciences \\ Al-Isra University, p.o.Box 22 \\ Amman 11622, Jordan
}

Tel: 962-79-66-78-263 E-mail: uniof@yahoo.com

Marzouq Ayed Alqeed

Assistance professor of Tourism

Applied Science University, p.o.Box 116

Amman 11931, Jordan

\begin{abstract}
The objective of the study is to examine how response data from direct marketing email campaigns could be utilized in measuring the development of a customer relationship in the context of an end-user loyalty program. The case analysed in the study is Club Sony Ericsson e-mail campaigns targeted at its registered members. The primary research problem covered in the study is "how can e-mail direct marketing results be measured by using Club Sony Ericsson existing campaign response and customer data?" In order to gain understanding of the role of e-mail direct marketing campaigns in a loyalty program, a framework is created around the concept of customer relationship. As a form of interactive marketing, e-mail direct marketing contributes to relationship development by providing a channel for dialogue that consists of both communication as well as interaction.

The empirical study is conducted by using a quantitative research method. Data analysis is performed in ways that could also be applied in ongoing monitoring of relationship development within the case company. The study focus is on the information that click-through data can provide when combined with variables found from the customer database. The study is conducted based on individual level secondary data available on recent Club Sony Ericsson e-mail campaigns, collected from campaign report files and Club Sony Ericsson member database. Click-through activity was found to have positive correlation with all the other behavioral variables available on the customer relationship. The youngest age group is found to have the lowest response rates. Repeat responses are rare within the studied time period. E-mail address invalidity is found to have significant effect on dialogue termination.

Analysing interaction data from e-mail direct marketing campaigns clearly provides new insight into the development of a customer relationship. Due to the relatively high frequency, tracking click-through activities enables monitoring relationship development in between monetary transactions and reflects the level of interest towards the loyalty program in particular. However, clicks on links in direct marketing e-mails should be mainly considered as a confirmation of interest rather than a requirement.
\end{abstract}

Keywords: Customer Relationship Marketing, Direct Marketing, Interactive Marketing, Loyalty Program, Dialogue, E-mail, Marketing Campaigns

\section{Introduction}

The marketing landscape is going through a transition phase that is driven by both shifts in marketing focus and developments in the available tools and technology. The subject of this study encompasses three new trends:

- New focus: build and manage customer relationships

- New media: communicate directly with customers by e-mail

- New information: capture customer behavior data on individual level

Companies are no longer satisfied with just talking to their customers, they would much rather have a dialogue with them in order to get to know them better and build lasting customer relationships. This means an increasing amount of the communication will take place through direct media. The high adoption rate of e-mail, the web's "killer app", combined with its ability to track message viewings and hyperlink clicks to individual recipients, is 
a highly attractive tool for relationship marketers.

Marketing is becoming less obsessed with winning over new customers and more focused on retaining the existing customers. Loyalty programs are introduced to reward customers who frequently purchase the same brand, with the intention of enforcing their loyal behavior and maybe even turning them into advocates of the brand. Instead of considering all buyers of a given product to be equally valuable, companies aim to evaluate the potential value that could be acquired from an individual customer during his or her lifetime and use this information for investing the marketing budget where it will reap the highest returns - their best customers.

Making decisions on which customers will be profitable in ten years time requires much more information than deciding how to maximize next quarter sales. While the amount of data available on customers is growing rapidly, it will not automatically turn into information that can be shared, let alone knowledge upon which to base the decisions. Communication and interaction with customers is increasingly moving into electronic media, which enables a whole new level of detail in measuring these activities.

\section{Theoretical Consideration}

The subject of this study is the measurement of e-mail direct marketing effectiveness. When used for building business-to-consumer relationships. The target is to gain understanding of the possible applications of e-mail campaign response data in measuring the success of customer dialogue, specifically when integrated into customer information found from internal company databases. The empirical research will test how the theoretical framework can be used to interpret individual level data and transform it into measures that surpass aggregate level indicators in providing insight into the communication process of e-mail direct marketing in the context of a loyalty program.

\subsection{Case Introduction}

The case analysed in the study is Club Sony Ericsson, which is the end-user loyalty program of Sony Ericsson Mobile Phones, the world's second largest mobile phone producer after Nokia. The program can be seen as a tool for building relationships between Sony Ericsson and its customers. Membership to Club Sony Ericsson is free to all Sony Ericsson mobile phone owners. The benefits offered include product and service information, customer support, digital content for mobile phones, invitations to special events etc. Club Sony Ericsson regularly uses e-mail and SMS direct marketing campaigns to keep in touch with its members. A more detailed description of Club Sony Ericsson and its activities can be found in this report.

\subsection{Purpose of the Study}

In order for direct marketing campaigns to be considered as customer dialogue in a relationship marketing sense, it is not enough to just talk to the customer through a direct media. One must also listen to what the customer has to say and adapt the outbound communication according to the response data received. Just like relationship marketing is shifting the product oriented thinking of mass marketing towards a customer oriented view, similarly the tracking of direct marketing communications needs to move from campaign level to relationship level analysis. Measurements of campaign response rates on aggregate level cannot accurately reflect how the relationship between the company and the customer is developing, especially in the context of one-to-one marketing where individual treatment of customer relationships is the foundation of all marketing activities.

Although the electronic media makes it possible to capture a wide variety of customer specific data, thus enabling individual level analysis of the relationships, the increasing volume of data also creates its own challenges. Monitoring single customer actions in a population of millions is impossible, which is why it is crucial to develop methods of analysis that take advantage of the customer dimension without drowning the user into a sea of detail. The information needs to be mapped to a conceptual framework that gives meaning to it; otherwise we face the danger of degenerating back to mass marketing measurement practices and losing one of the most significant advantages of using interactive media.

Documentation on the practical applications of theoretical frameworks in the area of relationship marketing utilising electronic media is still scarce. One reason for this is likely to be the uniqueness of various CRM systems that have been customised to the needs of particular companies. Applying generic measurement models in an environment where the availability and definition of data varies not only between each case but also over time is not a straightforward task.

The objective of the research from Club Sony Ericsson perspective is to study how the customer and campaign data currently available could be used in increasing understanding of the e-mail communication process that takes place between Club Sony Ericsson and its members on a regular basis. The information systems involved in the process are being developed to include functionalities required for continuous tracking of campaign results 
on customer level, but until now there has not been a practical way of combining the data, which has meant its potential has been left mostly unexplored.

The research includes an empirical part in which a sample of the two separate data sources, the Club Sony Ericsson Data Mart (a customer database used for analytical purposes) and the e-mail campaign response reports, will be combined in a manner similar to which will likely become possible in the customer database through the development of Club Sony Ericsson campaign management platform. The objective is therefore to examine the ways in which this data can be used for analysis purposes, so that the findings can be later applied to the planning of regular reporting.

\subsection{Research Problem}

The primary research problem discussed in the study is "How can e-mail direct marketing results be measured by using Club Sony Ericsson existing campaign response and customer data?"

Sub-problems to be solved in the study are:

"In which ways do e-mail campaigns contribute to the development of a relationship between Sony Ericsson and its customers?" Defining the purpose of the activity under investigation, examining Club Sony Ericsson e-mail direct marketing in a theoretical context.

"What information is available regarding the communication process?" Assessment of data availability and processing possibilities.

"How can this information be linked to the customer relationship?" Meaning of data in terms of the activity's purpose, identifying validity problems.

"What is the key information to be gained from the linkage concerning past mailings' effect?" Findings from the analysis of sample data.

"How could this information be monitored on a long-term basis?"

\subsection{Limitations of the Study}

The study focuses only on activities related to e-mail direct marketing as one element of the loyalty program. It does not discuss measurement of the overall success of such programs in managing customer relationships nor the return on investment derived from the use of e-mail in establishing a customer dialogue. While the ultimate purpose of relationship marketing activities is to drive up variables such as customer retention, share of wallet and value per relationship, their measurement does not fall within the scope of this study.

The study focuses on member activities that are directly traceable to the outbound communication, which in the context of the empirical research is limited to clicks on the hyperlinks provided in e-mails. The member in question is identified from the click stream data and the information is linked to profile and behavior data held in the customer database. Due to the long repurchase cycle of mobile phones and the limited amount of available data, the study will not focus only on phone purchases or the value acquired through them. The key phenomenon under investigation is the forming of an active relationship between Club Sony Ericsson and the members of the loyalty program, and how the e-mail direct marketing activities contribute to the development of this relationship.

\section{Theoretical Framework}

\subsection{Relationship Marketing}

Since 1970 the core phenomenon of marketing was considered to be the exchange of products for money. In this form of marketing, often labeled in literature as transaction marketing, the major focus has been to make customers buy, whether they are old or new customers. Marketing became campaign oriented, as the customers needed to be won over and over again. The marketing mix management approach and the 4P's model were the results of research on this exchange phenomenon. (Grönroos, 1997, 21.) Today the focus of marketing discussion is shifting away from the mass media thinking of the 4P model. In what has often been called a paradigm shift, the attention of marketers is increasingly focusing on buyer-seller interactions. This shift is based on the notion that it is not exchanges that are the core of marketing, but that exchanges take place in ongoing relationships between parties in the marketplace. This relationship perspective states that continuous purchases and cross-sales opportunities follow from well-managed relationships, thus seeing relationships as the most important concept in marketing. Grönroos (1997, 267) defines relationship marketing as a set of relationships, networks and interaction, where the value for parties involved is created through an interaction process between suppliers, customers, competitors and others. Companies benefit from the relationship marketing approach through 
increased customer retention and marketing productivity, and the customers receive added value through more customized service and products.

Whereas the exchange perspective in marketing is focused on the value distribution process, the relationship perspective focuses on the value creation process. Instead of distributing ready made value to customers, relationship marketing aims to facilitate and support the customers' consumption and usage processes throughout the relationship, in which value for customers is created by the customers and in interactions with the supplier or service provider.

\subsubsection{Customer Relationship}

According to Grönroos (2000a, 33) a relationship has developed when the customer perceives that a mutual way of thinking exists between customer and supplier or service provider. This definition emphasizes the attitudinal nature of a relationship. A firm should create interaction and communication processes that support this feeling, but it is ultimately the customer who determines whether or not a relationship has developed.

Grönroos (2000a, 35) categorizes customers as being in three different "modes" depending on their interest in a relationship with the firm in a given marketing situation: transactional mode, passive relational mode and active relational mode. In transactional mode the customer's interest is focused on making a successful purchase and he or she can perceive continuous communication between purchases, such as an e-mail newsletter, simply annoying and time consuming. Customers in passive relational mode are looking for the knowledge that they could contact the supplier or service provider, by for example finding an e-mail address printed on a soft drink can, but they seldom respond to invitations to interact. Active relational customers are looking for opportunities for interaction in order to get additional value and they can get disappointed due to a lack of contacts.

The categorization points out that one should not always expect a customer to show high levels of interaction, even if he or she does perceive the relationship marketing activities to deliver added value. As stated by Grönroos $(2000 \mathrm{a}, 36)$ "for customers in a passive relational mode, a relationship-oriented marketing strategy is important, although it may not seem so." Relationship marketing activities can increase the value of a brand in the minds of a customer in either passive or active relational mode, regardless of interactions. Feurst $(1999,163)$ brings out the inconsistent nature of actual customer behavior through an example of a young customer's typical preferences. If you give a youngster the chance to choose between a supplier that wants to create a learning relationship by recording the customer's personal data and a company that simply hands out the ready made product in exchange for payment, he or she is likely to choose the latter one. The choice is made regardless of the fact that the first alternative would be more beneficial to both the customer and the society in the long term. The example aptly demonstrates the need to explicitly communicate the relationship benefits to a customer in order to persuade him or her to switch from transactional to relational mode, as the behavior of an individual is often driven by short-term benefits. In examining consumer attitude towards forming relationships with suppliers, Peppers \& Rogers $(1993,327-328)$ describe the transactional marketing approach of using mass media to communicate your message to consumers as an implicit bargain. The mass marketers pay a portion of a magazine's production cost and in return the readers view their ads. Due to the implicit nature of this bargain, consumers are free to ignore the ads and mass marketers may freely harass many consumers with their message in order to enlist a few new customers. When using any addressable, two-way medium, the company and the customer make an explicit bargain, in which the parties collaborate and give something (service, information) to get something in return. The explicit bargain is based on mutual trust between the parties, which is an essential ingredient in any relationship and can therefore be seen as a requirement for converting customers from transactional to relational mode.

\subsubsection{Customer Loyalty}

Customer loyalty can be defined as the degree to which customers are predisposed to stay with a company and resist competitive offers (Peppers \& Rogers Group, 2002). As a measure, customer loyalty is the proportion of times a purchaser chooses the same product or service in a specific category compared to the total number of purchases made by the purchaser in that category (Neal 1999,21). While relationships are a central part of loyalty, they alone are not enough to make a customer loyal.

The process of building customer loyalty is often described using a loyalty ladder with five ascending steps: suspect, prospect, customer, client and advocate. The purpose of relationship marketing activities is to move the customer through a series of steps that culminate in the customer being an advocate for the company's product. (Roberts \& Berger 1999, 10-11.)

Frederick F. Reichheld demonstrated the economics of loyalty in his 1996 publication "The Loyalty Effect" 
through examples from various lines of business, all of which showed a clear correlation between customer retention and company profitability. He argued that while most managers understand the linkage which both customer and employee loyalty has on revenues and costs, they are blinded by short-term financial indicators which drive them towards maximizing shareholder value instead of value to the customer. (Reichheld, 2001, 12-16.) Drawing comparison between the concept of loyalty and commitment in the context of the development process of a relationship, Dwyer et al $(1987,19)$ suggest that commitment should be measured by three criteria: inputs, durability and consistency. The first criterion of commitment is that the parties in a relationship provide relatively high levels of inputs to the association. This can mean significant exchange of economic, communication, and/or emotional resources. Second, there should be some durability of association over time. The parties need to have a common belief in the effectiveness of future exchange, which will enable them to bond and encourage the continued investment in the relation. The third aspect of commitment is the consistency with which the inputs are made to the association. Inconsistency in input levels reflects low commitment and leads to a reduced reliance by the other party on the outcomes of the exchange. Social bonds tend to weaken and dissolve over time unless actively maintained. (Dwyer et al1987, 19.)

\subsubsection{Relationship Value}

The importance of customer loyalty becomes evident through the study of customers' value to the company depending on the length of relationship. A customer's contribution to net profit may vary substantially over the lifetime of the relationship. New customers who may initially be unprofitable will increase their profit contribution as the relationship continues, thus making it essential to study the life cycle of a customer when determining the value of the relationship. The lifetime value of a customer relationship to the company can be calculated as the net present value of the net profits that can be expected over the years. In order to estimate the future behavior of a customer, existing or new, historical data is needed for calculating actual repeat purchases that have taken place and projecting model for expected future purchases. (Roberts \& Berger 1999, 180-182.)

Although marketing literature mainly includes models of the value of a customer, in the context of relationship marketing one should also pay attention to the value-to-customer perspective. Philip Kotler $(1997,412)$ defines customer perceived value as the sum of core solution and additional services divided by the sum of price paid and relationship costs.

Relationship costs follow from the customer's decision to engage a relationship with another party. These costs can be of monetary or psychological in nature, ranging from membership fees to feeling of inconvenience. If the costs become greater than the benefits from the additional services, the customer is likely to prefer a transactional mode approach instead of relational mode.

The most loyal customers are commonly considered to be also among the most profitable ones, but the evidence behind this assumption is not unambiguous. Reinartz and Kumar (2002, 4-12) suggest that the relationship between loyalty and profitability is much weaker and subtler than what has been claimed in loyalty literature. Their study found little or no evidence that customers who purchased steadily from a company over time would be cheaper to serve, less price sensitive, or particularly effective at bringing in new business.

Reinartz and Kumar (2002, 4-12) found that loyal customers tend to be even more price sensitive than an occasional customer. These customers are generally more knowledgeable about product offerings and can better evaluate their quality.

Furthermore, consumers seem to strongly resent companies that try to profit from loyalty, since they believe loyal customers deserve lower prices. With this in mind, it is clear that one should not use measurement of customer loyalty as the single indicator of relationship value, nor should one aim to make all existing customers loyal to the brand.

\subsubsection{Customer Dialogue}

Dialogue is defined as an exchange of thought between two or more parties. According to Peppers and Rogers (1993, 213-215), there are four criteria that any marketing communication must meet before it can be considered to be dialogue with individual customers:

All parties to a dialogue must be able to participate in it

All parties to a dialogue must want to participate in it

. Dialogues can be controlled by anyone in the exchange

. Your dialogue with an individual customer will change your behavior toward that single individual, and change that individual's behavior towards you. 
A dialogue can be seen as an interactive process of reasoning together so that a common knowledge platform is developing. The process aims to build shared meanings and create new knowledge, so that the knowledge platform enables the supplier to create additional value for the customer on top of the value of goods and services that are exchanged.

Successful development of a relationship requires the parties involved to share information about needs that have to be fulfilled and solutions that can be offered. A distinction should however be made between sharing information and persuasion or manipulation. According to Grönroos (2000, 6), "relationship marketing frequently fails because marketers rely on relatioship-like, but nevertheless manipulative, one-way communication, such as personally addressed and even personalized direct mail, to lure customers into business with the firms they represent without listening to their wishes and responding to the feedback they may give."

In a dialogue there are no senders or receivers, only participants. Participation in a dialogue takes place through interactions between the firm and its customers, but also one-way messages, such as advertisements, brochures and direct mail, can be considered a part of the dialogue process. When such messages and interactions between the customer and the firm support each other, they are contributing to the development of shared meanings and new knowledge in a dialogueWith this in mind, the relationship dialogue process can be divided into planned communication process and interaction process. The first one includes communication messages which are planned and where separate and distinct communication media are used, ranging from TV commercials to exhibition stands. The latter one is a real process where the customer's interactions with physical products, service processes, systems and technology, e-commerce processes etc. occur. When these two processes get linked into a sequence, such as a customer calling a help desk based on a TV commercial, the consistency of communication messages becomes critical to relationship development.

Direct marketing messages often include an invitation for the customer to respond to the message. If a response is received, this may be considered the beginning of a dialogue or perhaps even as the manifestation of a dialogue. However, not all contacts between the parties having a dialogue need to include an invitation to respond, if the information provided contributes to the development of a common knowledge platform.

When analyzing the types of communication messages involved in a dialogue process, it is important to remember that also the absence of communication send a distinct message and therefore contributes to the process.

Effective relationship marketing dialogue should not be focused only on trying to make a sale with each contact. Having an interesting conversation consisting of more than pure sales talk with the customer can deepen the relationship and reap benefits over time through increased loyalty. (Peppers \& Rogers, 1993, 215.)

\subsubsection{One To One Marketing}

Don Peppers and Martha Rogers introduced the concept of one to one marketing in 1993 in their book "The One To One Future". It was based on a notion that recent developments in technology had generated a point of discontinuity that allowed companies to start competing for business opportunities one customer at a time. By using interactive media to create dialogues with individual customers and mass customization to tailor products and services to meet their expressed needs, it would become possible to provide the customer superior value compared to the traditional way of doing business, which is based on making products for large segments and promoting them through mass media. (Peppers \& Rogers, 1993, 7, 10, 15.) One to one marketing is a type of relationship marketing that focuses on the individual customer. Its basic idea can be simplified to "treat different customers differently". Being a customer-oriented company has usually meant being oriented to the needs of the typical customer in the market, meaning the average customer. The one to one ideology requires tracking the interactions of individual customers and acting according to this exact information instead of statistical averages. (Peppers \& Rogers, 1999, 1.)

By recording information about every interaction with the customer and customizing the product and service accordingly, a company can establish a learning relationship with the customer. This type of a relationship becomes increasingly valuable to the customer as time goes by, which also means competitors' ability to offer the same level of convenience decreases, thus locking the customer into the existing relationship by offering superior value. (Peppers \& Rogers, 1999, 2.) Individual level information on customers has been used in marketing long before the adoption of IT systems, but marketing theory has focused on mean values and masses (Gummesson, 1998, 146). With the introduction of new tools that make it possible to target marketing activities to individual customers instead of customer segments, it will no longer be acceptable to rely solely on aggregate measures when managing customer relationships. 


\subsection{Customer Relationship Management}

Customer relationship management $(\mathrm{CRM})$ is a subject that has been discussed in management literature since the 1960's, but its implementation has become a hot topic only recently. CRM can be described as the discipline of identifying, attracting and retaining a company's most valuable customers. According to Curry et al (2000), "the true business of every company is to make customers, keep customers and maximize customer profitability."

CRM is based on the notion that not all customers are equally valuable to a company. Following the Pareto principle frequently cited in business literature, the top $20 \%$ of the customers normally deliver $80 \%$ of revenues. More importantly, the top $20 \%$ of the customers deliver more than $100 \%$ of profits, meaning the majority of customers are actually unprofitable. It is therefore vital for a company to target its marketing efforts towards retaining the top $20 \%$ of existing customers rather than spending it on communicating with non-customers who are likely to be unprofitable. (Curry et al 2000, 17-21.)

Identifying the most profitable customers has been a difficult task, but the development of analytical techniques such as data mining and the increasing amount of electronic customer touchpoints like web sites has enabled companies to start pursuing this goal with a whole new level of intensity (Curry et al 2000). Due to its heavy reliance on technological advancements, many have started to consider CRM as a combination of software and business processes rather than purely a marketing strategy. While it is not reasonable to ignore the technical aspect when discussing CRM, one should remember that technology only provides tactical tools for implementing a company's customer relationship strategy. (Greenberg 2001, 32.)

\subsubsection{Direct Marketing}

Tapp $(2000,10)$ defines the concept of direct marketing with the following statement: "Direct marketing is a way of acquiring and keeping customers by providing a framework for three activities: analysis of individual customer information, strategy formation, and implementation such that customers respond directly." Roberts and Berger $(1999,3)$ add the distinction from junk mail in their definition stating "database direct marketing is an information-driven, relational marketing process that takes place in a context of concern for the privacy of customer data."

According to Tapp $(2000,4)$, "the key to modern direct marketing is the capture of individual customer details at the first sale, so that the marketer can begin a relationship with that customer, subsequently treating them differently over time in order to generate repeat business". This demonstrates the natural linkage between direct marketing and concepts such as relationship marketing and CRM, as they all revolve around the same key principles.

The terms direct marketing and database marketing are often used interchangeably. The general distinction made between the terms by Tapp $(2000,6)$ points database marketing towards strategy formulation, whereas direct marketing is focused on direct communication to customers. As suggested by its name, engaging in database marketing requires the company to maintain or have access to a marketing database. The definition of a marketing database provided by Tapp $(2000,29)$ states it as 'a list of customers' and prospects' records that enables strategic analysis, and individual selections for communication and customer service support. The data is organized around the customer". Roberts and Berger $(1999,165)$ further add that the content of the database has been collected over a considerable period of time.

A database holding records on individual customers is the basis of direct marketing activities: marketing analysis, planning, implementation of programs and control of all this activity. The advantage drawn from this database centric approach, compared to general marketing, is that it forces a natural focus on customers rather than products, again enforcing the natural linkage to relationship marketing ideology. (Tapp, 2000, 3-4.)

\subsubsection{E-mail marketing}

E-mail is one of the most interesting new channels enabling interactive marketing.

Kinnard (2000, xviii) defines e-mail marketing as" the act of sending marketing communications to recipients who first request it". This definition makes a clear distinction between permission based, targeted e-mail marketing and unsolicited, untargeted mass mailings often referred to as spam, which has to some extent given email a bad reputation as a contact medium in commercial relationships.

The key advantages of e-mail compared to traditional direct media are the following:

Cost-effective contacts

Preferred method of communication for many people 
Seen as a personal medium

Can be customized for each recipient

Allows easy interaction

Interaction can be tracked and the effects measured.

One of the underlying assumptions behind a permission based approach to marketing is that a customer who has given permission to be contacted by the marketer is a better, more loyal, and more profitable customer overall. Combined with the fact that most email users find unsolicited e-mail marketing messages as intrusive and many of them have started to take measures in trying to protect themselves from receiving spam, there is little reason for any e-mail marketer to attempt building a relationship with customers without first acquiring their permission. (MacPherson, 2001, 14-17.)

There are two main strategies for acquiring contact permission from the customer: option and opt-out. The opt-in policy means that the customer must explicitly state he or she gives the permission to be contacted by e-mail. This type of permission can be asked in, for example, the registration process of signing up for a username to an online service.

The opt-out policy requires the customer to actively unsubscribe from the e-mail contacts if he or she does not wish to receive them. A typical method of using opt-out is to send the message to a list of e-mail addresses acquired from external sources and provide the recipients with the option to remove themselves from the list by clicking on a link or replying to the message. (MacPherson, 2001, 15.)

The opt-out policy is not a recommendable approach if the target of e-mail direct marketing is to build lasting customer relationships. It takes the power away from the customer in favor of creating opportunities for the marketer. Because customers do not ask for opt-out based communication, the messages are unanticipated and often irrelevant, which makes them far less effective than opt-in e-mail messaging. (Godin, 1999, 229-230.)

\subsubsection{Relationship Measurement}

Measures used in traditional accounting have taken several centuries to develop into the status where they are today. Compared to this, measures of loyalty are relatively new and untried, and more importantly, not even applied yet in most companies. Measures are the business idiom that shapes the attitudes and behavior of a business organization. (Reichheld, 2001, 217-220.) It is therefore clear that customer relationship measures are a prerequisite for shifting management focus from the income statement to the customers.

The development process of a relationship includes interactions and communication between the supplier and the customer. Interactions are exchanges of goods, services, information or any other contacts that occur between the two parties. While communication takes place in all interactions, there is an additional series of planned communication efforts, such as direct mail or advertising. These interactions and communication need to become integrated into one value-creating relationship process over time for a relationship to emerge. Marketers should try to monitor this development in order to measure the existence of a relationship, even if creating ideal measurement instruments for this process may not be possible. It should however not be used as the only measure since there are typically many reasons for a customer to continue buying from one supplier. Low prices can keep up repeat sales, as can a convenient location, technological barriers, limited knowledge of competing offers etc. There can be several bonds that keep a customer attached to a firm, even though the customer does not feel that there is any relationship with that firm. Removing these bonds can result in losing the customer that was thought to have a relationship with the firm.

Payne and Frow $(2001,800)$ advice to treat with caution the kind of measurement systems that provide aggregated measures of profit, customer satisfaction and employee attitudes as they may overlook individual differences. For example, increasing the overall retention rate of customers does not necessarily result in significant profitability improvements, since increasing the retention of unprofitable customers can destroy profits. This is why relationship marketing requires measurement systems that allow companies to analyze their customer base and measure profitability on individual customer level.

The customer data upon which the measurement is based can be divided into two categories: demographic and behavior data. Demographic data can include information about customer age and gender, social status, area of residence, magazines read etc.

Behavior data tells about customer activities, such as purchases, call center contacts or web site visits. Of these two profile types, behavior data is likely to change more frequently as new information is collected on interactions between the customer and the company. This is one of the reasons why customer behavior is also a much stronger predictor of the future relationship than demographic data. (Novo 2000, 1.) Capturing the 
necessary data for measuring relationship marketing activities can sometimes be challenging. Relationship marketing requires a two-way flow of information, but according to Schultz $(1993,28)$, this does not mean that the customer has to give the information knowingly. Behavioral data captured from various interactions made through digital touch points can be just as valuable as information gathered explicitly from the customer.

\section{3}

\subsubsection{RFM Analysis}

Recency, Frequency, Monetary analysis (RFM) has been used in direct marketing for almost 40 years as a method for increasing response rates. It is based on both a priori reasoning and empirical evidence of customer behavior. A typical way of applying the method on a database of customers is to assign an RFM score to each record in the database and use these scores to target the marketing activities towards the most responsive customers. (Hughes, 1996.) RFM analysis is founded on the discovery that people who have bought from you recently are much more likely to respond to a new offer than someone who had made a purchase in the distant past. The frequency of purchases made also has a positive impact on rate of response, as does the total monetary value of purchases. However, out of these three variables, recency has been found to be the strongest indicator of willingness to respond to an offer, hence its ranking as the first variable in the term RFM. (Hughes, 1996.)

Through the increasing number of information systems involved in customer interactions, a wealth of non-purchase related data is also available in modern customer databases. This has extended the potential applications of RFM analysis, as the same laws that predict purchase behavior also apply to other types of customer behavior, such as web site visits, sign-ups or surveys. (Novo, 2000.)

Whereas the modeling of demographic and other profile variables result in a near static picture of the customer, RFM measures actual behavior and can therefore provide a more accurate prediction of a customer's likelihood to respond (Hughes 1996). Customer migration between different cells of an RFM value grid can give an up-to-date view of how recent marketing activities have affected customer behavior. In the durable goods business, where the typical re-purchase time of a particular product is several years, recency alone is not a practical measure for predicting customer repurchase likelihood. In a single product perspective, one should look at recency of purchase relative to the expected life of the product, not recency of purchase from the actual purchase date. In a whole relationship perspective, recency increases the relative likelihood of a customer engaging in purchase behavior with the business regarding other types of products on offer. (Novo, 2001.) Reinartz and Kumar (2002, 86-94) criticize RFM models for their lack of proper distinction between frequently and infrequently bought goods and suggest that an event-history model should be used instead when the pacing of customer interactions is slow. Many companies offering long purchase cycle products actively shorten the cycle by employing an inter-purchase contact strategy. By building an active dialogue with the customer, the company can "bridge" the purchase cycle and maintain recency of contact, which can work in a similar manner as recency of purchase (Novo, 2001). This approach increases the value that can be derived from using an RFM model in the area of infrequently bought goods.

\subsubsection{The Leaky Bucket Theory}

Measuring customer migration is a way of digging deeper into aggregate measures such as total revenue or profit growth from one fiscal year to the next. By measuring the buying behavior of the customer base over a period of time it is possible to see some of the underlying patterns that cause the changes on the bottom line. One metaphor commonly used for illustrating these changes is the "leaky bucket" theory. (Rongstad, 2001.) Growth in revenue or profits from one period to the next acts like a leaky bucket is being filled with water. The water level in the bucket rises as new customers are added and revenue from existing customers increases. The bucket also has several leaks from customers who stop purchasing or decrease purchase volume from a prior period. If you only measure how much the water goes up or down from one period to the next, it is not possible to make appropriate decisions on how to increase the total amount of water in the bucket. (Rongstad, 2001.) Tracking transaction information at the customer level allows the analysis of customer migration by identifying what happens to individual customers from any one period over to the next. Although customer migration can be reported in an aggregate format, its value is derived by measuring actions at the individual customer level. Customers can be grouped according to lifetime value, RFM score or any other relevant variable for analysis purpose, but the migration patterns are calculated based on detailed transaction data that can be captured where customers identify themselves, for example by showing their loyalty program membership card. (Rongstad, 2001.) 


\subsection{Available Data}

The second sub-problem of the study is "what information is available regarding the communication process?" In this content the possible current data sources and their contents will be described.

\subsubsection{Campaign Report Summaries}

For each e-mail campaign sent by $\mathrm{CN}$ a campaign report is generated. These include both a collection of summary values for selected campaign sending variables as well as detailed click data on each click-through made by the recipients. The summary variables available in these reports are:

Number of recipients (= unique e-mail addresses)

Number of e-mails successfully sent

Number of HTML e-mails read

Number of clickthroughs

Number of hard bounces

Number of soft bounces

Number of unsubscribe

These variables constitute the key information that has been used for the regular monitoring of e-mail campaign performance over a period of time. The problem with this type of measures is that they view the communication purely from the perspective of running an e-mail sending process, rather than maintaining a dialogue with individual members. Message viewings and link click-throughs remain isolated events with no relation to the past communication and interactions with members. This means the information does not contribute to the development of a common knowledge platform and added value cannot be created based on the reasoning process.

\subsubsection{Campaign Click Data}

The detailed response data found from the campaign reports include the following

Variables:

. Message ID

URL ID

E-mail address

Date and time of click-through

Due to limitations in the mailing platform used, the unique member identifier (CID) is not included in the click data. This means the data has to be linked to member information from $\mathrm{CN}$ database by using the e-mail address as the key field. The shortcoming of this approach is that while the CID's will always remain constant, the email addresses can vary over time if members update their contact information. Therefore the accuracy of historical response data will steadily decrease if CID's are not associated to the response data. Another problem with using the e-mail address as key field is that several CID's may share the same address.

Since the click data is currently not imported into the $\mathrm{CN}$ database, there is no categorization available for the URL's. Depending on the contents of the e-mail messages, the URL's may lead to the CN web site, sony ericsson main web site, a dedicated landing page (designed specifically for the promotion), a third party site or an unsubscribe page. In order to enable the analysis of overall e-mail campaign effectiveness, the URL ID's should be encoded to include information regarding the general purpose of the link.

The timestamp information recorded for each click-through makes it possible to monitor the e-mail sending process by, for example, analyzing what is the distribution of clicks over time compared to the time of message sending, which could give an indication of the optimal timing for e-mail campaigns. Consecutive clicks on the same link by the same recipient could be used for assessing members' level of interest towards the subject of the link. This could however lead to false conclusions in situations where problems in web server performance increase the load times of the page and therefore make members click on the links repeatedly.

\subsubsection{CN Member Database}

The CN Data Mart is a member database used for analytical purposes. It contains most of the member and service related information available in $\mathrm{CN}$ production databases and its data is updated on a daily basis. Following the categorization of customer profile data into demographic and behavioral data (Novo 2000, 1), the contents of the Data Mart can be described with the following summarization. Demographic data: 
Gender and age

Registration date and media

Contact details

Contact permissions

Behavioral data:

. Product registrations

. Digital content downloads

. Campaign contacts

Inbound contacts

Phone repairs and swaps

Although the Data Mart is used only for data analysis and campaign management purposes, its design resembles a production database in the sense that the behavioral data is mostly available in only transactional format, with only few fields summarized to member level. While the transaction level data is useful in performing detailed analysis of a particular behavioral item, the database design inhibits combining these items for studying their interrelationships. The query structures become too complex for the end user and query performance is reduced to unsatisfactory level. Since summary data fields cannot currently be added into the Data Mart, certain types of data analysis require the data to be exported into an external database.

\subsubsection{Data Interpretation}

The third sub-problem of the study is "how can the communication information be linked to the customer relationship?" This chapter discusses first the different problems and shortcomings related to associating the data to relationship concepts and then concludes how the data items can be mapped to the theoretical framework.

\subsubsection{Definition of a Member}

The terminology used for labeling concepts of the $\mathrm{CN}$ information system can be misleading if they are directly compared to their counterparts in the real (physical) world without interpreting their meaning. One potential misinterpretation is related to the term 'member'. (In the actual data model of the $\mathrm{CN}$ databases this concept is referred to as 'customer', but since the terms are in practice interchangeable, the database concept is also referred to as 'member' in this document.)

$\mathrm{CN}$ operates in the area of business-to-consumer relationships; therefore the default interpretation of a member is one physical person. Ideally the business information systems should contain a corresponding model of reality, but in one cannot assume each member record in the $\mathrm{CN}$ database to represent one physical person. A single person can have multiple member records and member ID's, or alternatively one member record may be used by several physical persons. Exploration of customer data held in the $\mathrm{CN}$ database has identified several occurrences of both cases and there is reason to believe their magnitude to be of significant level.

The underlying logic behind CN's registration process is that every unique person should create one member account for him or herself and register all future product purchases on this same account. However, in reality the person registering further Sony ericsson products may have either forgotten the information necessary for accessing his or her account information, or alternatively forgotten about the prior interactions with $\mathrm{CN}$ completely, thus not acknowledging the existing member account. This can easily lead to creation of multiple membership accounts for one physical person. The reverse scenario, using one member account for registering products from several physical persons, could occur if, for example, people assume having more registered products on the same account will entitle them to more benefits from $\mathrm{CN}$.

\subsubsection{Definition of Purchase}

Unlike in many other lines of business where loyalty programs have traditionally been used, there is no direct interaction between Sony ericsson and the CN member when he or she purchases a new product. Mobile phones are sold through retailers and operators, which means $\mathrm{CN}$ is an entity independent from the retail channel. This creates an additional challenge for collecting information on purchases made by $\mathrm{CN}$ members. Whereas a grocery store chain needs to teach the members of its loyalty program to show a membership card during the check out procedure, $\mathrm{CN}$ has to go one step further and get the members to perform a separate registration procedure in addition to the purchase transaction.

It is obvious that the barrier for members to identify themselves is higher when a dedicated procedure is required for registering a purchase. This is likely to result in a lower rate of data capture, thus decreasing the accuracy of member purchase history as a measure for determining the loyalty program's results. 


\subsubsection{Repeat Purchases}

From the data point of view, it would be easy to assume that the number of registered phones per each member would indicate the number of Sony ericsson products he or she has purchased. The shortcoming of this approach is that it ignores any previous customer relationship the person may have with Sony ericsson prior to signing up as a $\mathrm{CN}$ member. Also, if an existing member accidentally registers his or her latest purchase to a new member account, all historical information is lost. This could even lead to a situation where, in terms of maintaining the common knowledge platform, it would have been better if the member would have ignored new product registration altogether. It is impossible for $\mathrm{CN}$ to identify when a member decides to purchase a mobile phone from a competing brand, as this activity does not result in any natural interaction with $\mathrm{CN}$. It is equally impossible to determine whether a member with several registered products has remained loyal to Sony ericsson between the registrations or if he or she has bought products from other brands during that time. Even though the majority of people are likely to have only one mobile phone in use at any given time, the $\mathrm{CN}$ membership cannot be used as proof of monogamous loyalty. A person who registers new Sony Ericsson products just as often as the average $\mathrm{CN}$ member might in reality be highly interested in mobile phones and switch between other brands in between the Sony ericsson product registrations. Still, by focusing only on the product registration data this person would not be identified as a particularly potential buyer of the latest mobile technology and CN might not provide him or her with the kind of treatment needed for increasing the brand preference towards Sony Ericson.

\subsubsection{Dissolution}

Although CN members have the opportunity to resign from the program, this is performed only if the members explicitly request their information to be removed from the records. This means there is no formal definition for relationship dissolution in a $\mathrm{CN}$ membership. In reality, the relationship between $\mathrm{CN}$ and its member can be considered to have come to an end when the two no longer have interactions, as suggested by Holmlund's (1997) model. The member may have either switched to using a competing mobile phone brand or continued as a Sony ericsson user, but due to the lack of contact there is no longer any exchange of information.

Since there are no concurring financial implications (such as an annual fee) resulting from $\mathrm{CN}$ membership, the easiest way for a member to discontinue the relationship is to simply ignore it altogether. Member accounts in the $\mathrm{CN}$ database gradually become inactive as no new data is recorded for them and contact details become out of date. As time goes by, an increasing share of member accounts will fall into this category. This should be taken into consideration when analyzing customer data, in order to avoid the inactive members' data from distorting or hiding the trends in active member behavior.

\section{Descriptive of the Research Methodology}

We discusses the methods and data used in the empirical research and the validity of results acquired from it.

\subsection{Approach and Methodology}

The empirical study was conducted using a deductive approach and quantitative research methods. The material used in the research consisted of secondary data that was available from two sources: the Club Sony Ericsson Data Mart (database) and e-mail campaign reports (flat files

One of the research objectives was to find a way to use existing $\mathrm{CN}$ member and campaign data for analysis purposes, both in ad-hoc research and also on continuous basis. Therefore the choice of data sources was naturally limited to internal resources.

Although the current format and location of the data meant there was a need for manual processing before the analysis could be conducted, most of the variables included had been generated through automated processes. The sample data was imported into a personal database that could in theory also be implemented in the live environment, thus making it possible to perform similar analysis on all $\mathrm{CN}$ members.

\subsection{Available Data}

The data available for analysis in $\mathrm{CN}$ was described earlier. Since the resources available for the study were in general identical to this description, only the limitations specific to the study are reviewed here. While the customer data and campaign aggregate data were complete, e-mail campaign response data was only available from a limited time period. The reports covered a time period starting from April 2002 and were available for a total of 49 campaigns in 23 countries. As one of the key phenomena to be studied was the effect of consecutive campaign contacts, it was important that the sample contained $\mathrm{CN}$ members who had received several mailings between April 2002 and September 2002 (the deadline set by the data collection schedule). Therefore it was not practical to include members from countries with only one campaign report available into the sample. It is also 
important to remember that not all members have received all the mailings. This can be due to campaign target group criteria, changes in member contractibility or new members having registered during the time period.

\subsection{Population}

The target population of the research was defined as "all Club Sony Ericsson (Europe, Africa \& Gulf region) members having been sent campaign e-mails between April 2002 and September 2002". The sampled population was limited to four countries (Austria, Ireland, Spain, Switzerland) due to their best availability of campaign response data (minimum five distinct campaigns). The member base of these countries covered around $12 \%$ of the e-mail contactable $\mathrm{CN}$ members at the time of the research. It was clear that the 23 countries in the population would differ considerably in terms of both their campaigns and member base profile. Since the available data as well as processing resources were limited, it was not considered feasible to attempt to cover all countries in the sample data. Focusing on four selected countries made it possible to analyse variations in results between them, instead of relying only on average data from the total population. As the purpose of the research was not so much in determining the behavior of an average $\mathrm{CN}$ member rather than in exploring the possible applications of individual level data, the selection of a limited sampled population was considered to be the optimal choice.

4.4 Sample

The sample members were selected from the CN Data Mart by using systematic sampling based on their unique member identifier (CID), which is a ten-digit number.

The last few digits of the CID are generated randomly for each member during their registration to $\mathrm{CN}$ and can therefore be used for sampling purposes. The possibility to use stratified sampling was inhibited by the structure of the source database that did not allow using a selection criteria consisting of both customer and campaign variables if reasonable query performance was to be preserved. $20 \%$ of the members in the sampled population were included in the sample, which meant the inclusion of 137,946 members. This data volume provided satisfactory accuracy and adequate processing performance. Behavioral data selected from the CN Data Mart transaction tables was summarized to member level for analysis purposes. Campaign contact data was selected separately based on the CID's of the members included in the sample, resulting in 557,872 rows of contact transactions. Campaign response data was collected manually from campaign reports. Due to the lack of a CID field in the reports, click data had to be joined to member data by using e-mail address as the key field. During the data collection process, any duplicate clicks per single link were removed. Campaign and link hierarchy was created specifically for the sample data and identifiers were added into the click transactions. The click data was included in its entireness and later linked to the sample members, resulting in a total volume of 109,663 clicks, out of which the sample members performed 21,019 clicks. The data was imported into an MS Access 2000 personal database operated on a desktop PC with a PII/400 CPU and 320MB of memory. The size of the database file at the end of the analysis phase was $115 \mathrm{MB}$. A description of the database structure used can be found in appendix B. Query performance with this setup was satisfactory throughout the analysis phase.

\subsection{Data Analysis}

The data was analyzed by building crosstab queries and exporting the query results to MS Excel for further manipulation. The click data was summarized to member, campaign and link level to simplify query structure. Temporary calculated fields were created by using sub queries when necessary, but the existing data categorization proved to be adequate in most cases. Since the CN Data Mart contained complete data sets for many of the variables used, on some occasions this live data was queried for information that was not available in the research database. This was done in order to acquire useful background information that was excluded from the research database due to the limitation of including only contacted members.

\subsection{Research Reliability}

Reliability is the extent to which an experiment, test, or any measuring procedure gives the same results on repeated trials conducted by either the same person or anyone else (McNeill 1990, 14-15). The use of secondary data from a computer environment means the data collection process was unlikely to suffer from random errors. The data was derived directly from information systems used in managing member data and sending email messages, therefore the results of a research repeated at a later time would likely be identical to the current findings.

There is no evident indicator suggesting the data integrity would not have been compromised during the mechanical processing involved in its original collection nor the manual processing conducted during the research. Although Club Sony Ericsson also sends e-mail campaigns through various local e-mail vendors, all the 
campaigns included in the sample had been conducted using the same vendor, which increases the reliability of the campaign data.

\subsection{Research Validity}

Validity can be divided into internal and external validity. Internal validity refers to the question of whether the results obtained within the study are true, whereas external validity is concerned with whether the findings can be generalized to other populations, settings or time periods. (Ghauri et al 1995, 33)

\subsubsection{Internal validity}

Compared to sampling methods commonly used in similar research projects, the volume of sample data included was substantially higher. The availability of secondary data resources that in many cases covered the whole population meant the research validity was not in practice threatened by sample size. It is however important to remember that the process through which the secondary data had originally been collected is not without its flaws, which is why considerations of internal validity should not be ignored. Customer entered data, such as gender and age, are subject to both intentional and unintentional errors. Unlikely age values ( 0 years, 150 years etc.) are to some extent excluded in the secondary data, but demographic data is also missing from a certain part of the population. Contact information (in this case e-mail address) validity is defined through automatic checking procedure as well as bounce reports on mailings sent, which limits the existence of (relevant) invalid addresses in the member database to a short time period between contacts. Credit purchase data cannot make a distinction between credits bought and credits given for free; therefore the events could not be considered monetary transactions and were therefore excluded from the analysis. Digital content downloads do not include downloads paid through operator billing, thus capturing download activity only partially. When compared to the average repurchase cycle of mobile phones and Sony Ericsson brand loyalty measured in surveys, it becomes clear that only a part of the members update their product information when acquiring a new Sony Ericsson phone. Another problem related to product updates is that some members may create a new account when switching to a new Sony Ericsson a model because they do not remember their member ID or password needed to access their account information. Reliable identification of defectors who have switched to another brand of mobile phone is impossible. Even repeat registrations are not $100 \%$ sure information, since some people may be using their membership account to register the phones of their family or employees. All these factors have to be kept in mind when analysing customer relationships through phone registration data.

Processing campaign response data required generating a key field to each of the data entries. The primary key used in Club Sony Ericsson Data Mart, the CID, does not exist in the click data; which is why the member e-mail address had to be used for linking the two data sets. This causes problems in the aforementioned case where a customer has registered two or more membership accounts that share the same e-mail address. These duplicates had to be removed during the process of linking customer data to click data. The logical method of performing the deduplication was to delete the account with an older registration date, as it was more likely to be the inactive one. This process can nevertheless cause marginal mismapping of the campaign response data.

\subsubsection{External Validity}

Limiting the sample population to a relatively short time period and to only some of the Club Sony Ericsson countries due to practical reasons is bound to decrease the applicability of the findings to the whole target population. The country selection was not performed with the intention of covering the variation in markets within the population, as there was no prior research on which the selection could have been based. In addition, the differences between the contents of all sent e-mails could not have been analysed within the scope of this study, which is why the attempts to increase internal validity through different selection criteria of the sampled population would have been unlikely to produce significant results.

The practices of using e-mail direct marketing in facilitating customer dialogue within $\mathrm{CN}$ are constantly evolving. Therefore the findings of the study cannot be reliably generalized to prior time periods. The findings should be considered as a snapshot from a given time period that can be used in the immediate planning of dialogue related activities and as a reference point for future research on the subject.

\section{Conclusions}

The final sub-question of the research was "how could the information be gained from the research be monitored on a long-term basis?" The recommendations for applying the research findings into regular measurement of the e-mail direct marketing activities will now be discussed in detail.

If we compare the previously available information on CN's e-mail driven customer dialogue, based on campaign level summary figures, to the new information provided by the research, we can see they provide very 
different views on the same phenomenon.

Campaign reports show how $\mathrm{CN}$ is talking to its members, whereas member level data gives an idea of how the message is received and, to some extent, how members are talking back at CN. Even though the data only covers one very specific part of the communication process, the click on a hyperlink, it clearly increases the amount of knowledge held on registered $\mathrm{CN}$ members and their behavior towards e-mail direct marketing activities.

The extent to which ad-hoc research similar to this study could be performed on different sample populations is in theory only limited by the availability of e-mail campaign reports. Comparing results from different time periods could enable measuring short-term effects of changes applied to CN's e-mail communications. Repeating the analysis on the same set of members included in this study would also be possible, if one wished to examine the effects of e-mail direct marketing on relationship development over time. Long-term monitoring of e-mail direct marketing effectiveness should not rely on ad-hoc research, but rather the information systems should enable the automation of repeated measuring activities. The following topics identify areas in which it would be beneficial to modify or develop the contents of data stored in CN's member database to better support the analytical needs.

\subsection{Member Activity Level}

The research found positive correlation between member click activity and other types of identifiable interaction, such as product registrations, inbound contacts or digital content downloads. Although the focus of this particular research was on the e-mail response data, in the context of analyzing member dissolution it should not be treated separately but rather be included in the set of other member activity indicators. The fact that members with clicks are also more likely to have other interactions with $\mathrm{CN}$ supports the assumption that these actions are interrelated and they form the natural path of an active relationship. They are one type of possible acts in a CN membership and should be considered as building blocks that grow into episodes, sequences and finally a relationship, as suggested by Holmlund's (1997) model.

The repurchase cycle of mobile phone products is quite long, which reduces the accuracy of member value analysis conducted based on static, demographic variables. This type of data mainly reflects the starting point of the dialogue, not its results or the development of a relationship over time. As pointed out by Reinartz et al (2002, 9), just because a group of customers was profitable in the past, does not mean it will continue to be so in the future. Many nonloyal customers can be very profitable initially, but if a company continues to invest in marketing to them after they have ceased their buying activity, these customers can become unprofitable in the long run. In order to improve the accuracy of member value measurement, the recency of last interaction should be included into the analysis and used in conjunction with product purchase information to determine the current state of the customer relationship.

Although the sample data suggests the frequency of interactions by a typical member is not high enough to justify weekly or monthly follow-up, knowing whether the last time a member was in contact with $\mathrm{CN}$ was two weeks or two years ago would be a strong indicator of response likelihood. The information could be acquired by adding a field into the member database which would calculate the latest date of interaction based on all the transactional tables (product registrations, digital content downloads, inbound contacts, repairs, swaps, and click-throughs when available).

\subsection{Member Profile Changes}

The current member data does not include information on when the variables stored in non-transactional format have been updated. This issue concerns mainly the contactability related data, such as contact permissions, contact details and their validity. There is no historical information available regarding the changes in contactability data, which makes it impossible to study how the potential of having a dialogue with members develops over time and in relation to member life cycle. Adding information on the date of last update of contactability related fields into the database would enable analysis of the reasons behind loss of direct contact to members, making it possible to take measures aimed at preserving dialogue.

\subsection{Response Categorization}

If detailed click-through data becomes available in the member database, information on the content of each e-mail message should also be recorded. Knowing only that a member clicked through a link provided in a particular message is not enough to interpret his or her behavior if the communication consists mainly of regular e-mail newsletters containing information on various different topics. Unless the destination page behind the link is described, it will be impossible to differentiate between links to product information pages, $\mathrm{CN}$ front page, external campaign sites and the likes. It is not feasible to expect the hyperlink structure of individual e-mail 
messages to be studied afterwards, but rather the process of sending out campaign messages should include a generic categorization of possible responses from recipients according to link purpose.

\section{Further Research}

The practical applications of using data from various electronic customer touchpoints that a modern loyalty program can contain have not yet been widely studied. There are numerous potential topics for further research that could expand our understanding of the key phenomena related to building a customer dialogue through electronic media. The following are some of these issues that were identified during the process of this study. In order to attract campaign responses from customers you have to first be able to contact them. As the $\mathrm{CN}$ case demonstrated, the validity of e-mail contact information collected for a loyalty program can deteriorate very rapidly if customer dialogue does not remain active. By the time an outbound e-mail message sent to the customer results in a hard bounce, the actual contactability has most likely already expired a long time ago and the bounce is just the final confirmation of this. It would be very useful for the e-mail direct marketer to be able to identify potential loss of contactability well beforehand, not only to reduce the amount of messages sent to obsolete mailboxes but to make it possible to act on the situation and preserve the customer contacts. Methods for analyzing the development of contact data validity in different environments should therefore be studied, as the validity information is likely to be available in most planned e-mail communication programs. When the collection of customer information is first initiated, all accounts in the customer database are often considered active and valid. As time passes by, an increasing share of the accounts will become inactive in the real world as a result of relationship dissolution. Transforming this phenomenon into a database process that identifies the inactive accounts is in many cases not performed until the volume of these accounts has started to distort data analysis and weaken communication accuracy. Since the phenomenon itself is of universal nature, the possible ways of taking it into consideration when designing information systems and methods of filtering existing databases should be studied. Although the exact definition of inactivity needs to be decided case by case, based on the average fluctuations in customer activity, using common principles could improve the reusability of models developed for tracking dialogue effectiveness. The time period examined in this study was not long enough to allow the inclusion of the time dimension into the data analysis. Continuous monitoring of relationship development is however a time dependent process where the focus is on customer migration between defined activity categories. The variables analyzed in this study provide a snapshot from a given moment, but the data stored in transactional format would also allow analyzing sequential events and constructing models to display the interrelationships of different activities in a more illustrative manner. By gradually increasing the level of detail involved, it could be possible to map the interactions specific to the relationship in question onto a hierarchy similar to the model presented by Holmlund $(1997,96)$. Understanding how this relationship structure can be made visible from the available data would enhance both planning and measuring of the planned communication process.

\section{References}

Colin, Eileen. (2001). Marketing Capitalizes On E-mail. InformationWeek, (2001-07-23) Issue 847, 55-56.

Curry, Jay \& Curry, Adam. (2000). The Customer Marketing Method. How to implement and profit from customer relationship management. New York. The Free Press.

DoubleClick Inc. (2002). DoubleClick Q2 E-mail Trend Report. (September 20002), [Online] Available: http://www.doubleclick.com/us/knowledge/documents/research/dc_consumer_email_0210.pdf

Dwyer, Robert F., Schurr Paul H., \& Oh Sejo. (1987). Developing Buyer-Seller Relationships. Journal of Marketing. Vol.51 (April 1997), 11-27

Feurst, Ola. (2001). One to one -markkinointi. Suomennos. Porvoo: WS Bookwell Oy. Hanifin, Bill (2001. Loyalty programs need knowledge base. Marketing News, (2001-08-27), Vol. 35 Issue 18, 23.

Gartner Inc. (2002). Loyalty Programs and the Web: Consumers Don’t See a Link. Research report, published (2002-10-24). [Online] Available: http://www.gartnerg2.com

Godin, Seth. (1999). Permission Marketing. Turning strangers into friends and friends into customers. New York. Simon \& Schuster Inc.

Gordon, Iah H. (1998). Relationship Marketing: New Strategies, Techniques and Technologies to Win The Customer You Want and Keep Them Forever. Ontario: John Wiley \& Sons Canada, Ltd.

Greenberg, Paul. (2001). CRM at the Speed of Light. Capturing and Keeping Customers in Internet Real Time. Berkeley: Osborne/McGraw-Hill. 
Grönroos, Christian. (1996). Relationship marketing: strategic and tactical implications. Management Decision, (34/3), 5-14.

Gruen, Thomas W., Summers, John O., \& Acito Frank .(2000). Relationship Marketing Activities, Commitment, and Membership Behaviors in Professional Associations.

Gummesson, Evert. (1997). Relationship marketing as a paradigm shift: some conclusions from the 30R approach. Management Decision, (35/4), 267-272.

Gwinner, K.P., Gremler, D.D., \& Bitner, M.J. (1998). Relational Benefits in Service Industries: The Customer's Perspective. Journal of the Academy of Marketing Science, 26(2), (1998, pp. 101-114).

Holmlund, Maria. (1997). Perceived Quality in Business Relationships. Helsinki: Hanken Swedish School of Economics, Finland/CERS.

Hughes, Arthur Middleton. (1996). Boosting response with RFM. Marketing Tools, Vol. 3 Issue 3, 4-8.

Kinnard, Shannon. (2000). Marketing With E-mail. A Spam-Free Guide to Increasing Sales, Building Loyalty, and Increasing Awareness. Second Edition. Gulf Breeze: Maximum Press.

MacPherson, Kim. (2001). Permission-Based E-Mail Marketing That Works! Chicago: Dearborn Financial Publishing, Inc.

McNeill, Patrick. (1990). Research Methods. Second edition. London, Routledge. Neal, William D. 1999. Satisfaction Is Nice, But Value Drives Loyalty. Marketing Research, Spring 99, Vol. 11 Issue 1, 20-23.

Novo, Jim. (2001). Customer Retention and LifeCycle Modeling in the High Ticket/Durable Goods Business. (2001-09-17), [Online] Available: http://www.drilling-down.com/Durable- Goods.htm.

O’Malley, Lisa \& Tynan, Caroline. (2000). Relationship marketing in consumer markets: Rhetoric or reality? European Journal of Marketing, Vol. 34 Issue 7, 797-815.

Payne, Adrian \& Frow, Pennie. (1999). Developing a Segmented Service Strategy: Improving Measurement in Relationship Marketing. Journal of Marketing Management, (1999, 15, 797-818).

Peppers, Don \& Rogers, Martha. (1993). The One To One Future. Building Relationships One Customer at a Time. New York: Doubleday.

Peppers, Don \& Rogers, Martha. (1999). The One To One Fieldbook. The Complete Toolkit for Implementing a 1 To1 Marketing Program. New York: Bantam Books.

Reichheld, Frederick F. (2001). The Loyalty Effect. Paperback. Boston: Harvard Business School Press.

Reinartz, Werner \& Kumar, K. (2002). The Mismanagement of Customer Loyalty. Harvard Business Review, vol. 80 issue 7, 86-94.

Roberts, Mary Lou \& Berger, Paul D. (1999). Direct Marketing Management. Second Edition. Upper Saddle River: Prentice-Hall, Inc.

Rongstad, Neil. (2001). Measuring Customer Migration: The Key to Stopping the "Leaky Bucket". Relationship Marketing Report, Vol. 1.10. (2001-12-03).

Schultz, Don. (1993). Marketing From the Outside In. Journal of Business Strategy, 14(4), 25-29. 